\title{
Using PESTEL Framework to Analyze User-Generated Content Usage on Social Media: The Case of Indonesian Tourism and Travelling Business on Instagram
}

\author{
S Paramadita ${ }^{1}$, A H Sasongko ${ }^{1}$, S Candra ${ }^{2}$ \\ ${ }^{1}$ BINUS Entrepreneurship Center, Management Department, Universitas Bina Nusantara, \\ Jakarta, Indonesia \\ ${ }^{2}$ BINUS Business School Undergraduate Program, Management Department, Universitas Bina \\ Nusantara, Jakarta, Indonesia \\ ${ }^{1}$ siti.paramadita@binus.ac.id, ${ }^{2}$ agunghari@binus.ac.id, ${ }^{3}$ seven@binus.ac.id
}

\begin{abstract}
The objective of this study is to empirically compare the effectivity of usergenerated-content usage throughout social media with other traditional advertisement medias such as television, radio, and printed media in terms of consumers' buying decision throughout Indonesia's tourism business. Nowadays, millennials generation tend to choose travelling experiences rather than buying goods. Furthermore, social media such as Instagram has played an important role in millennials generation's life; they engage in social media on a daily basis. This study used mixed method approached with PESTEL Framework as qualitative method and questionnaire deployment as quantitative method resulting in exploratory sequential research design. Questionnaires has been deployed to 245 social media users and the data was processed with SPSS. Based on the research applied, user-generated-content usage inside Instagram application as new marketing media for Indonesian tourism business has proven to be more effective compare to other traditional marketing media as people intend to trust words-of-mouth better than far-fetched traditional advertisements.
\end{abstract}

Keywords: PESTEL, Instagram, Social Media

\section{INTRODUCTION}

The digital society era is inevitably has thrown up a new culture to the consumer world. The fast and massive usages of social media, such as online social networking sites (SNS), have been accompanied by rapid changes in consumer behaviour. Sites like YouTube, Facebook and Instagram have proliferated and significantly growth in this sector has been amazing. According to Wikipedia, there are up to 120 SNS goes online. This growth has been predicted there are high request to facilitate social contact between site users.

Today's consumers are seeking for the relevance of a product with their needs, wants, and the present emerging culture. Indicating that a product should be authentic. Word-of-mouth (WOM) reports are seen as major motivating factor in many purchase decisions [1] The swift change of the internet with its much-enhanced communication capabilities has intensely 
increased the rule and possibility of WOM and blowouts it worldwide. WOM in early days is User-Generated Content.

Research has shown that WOM, in the methods of reviews, comments and evaluation are influential in prompting and persuading consumers [2]. So, WOM becoming one of killers advertising in the internet that more proven than advertisement that produce by company itself Where WOM in the era of social media is User-Generated Content (UGC). In the hospitality services industries, UGC has become a current tool tourist use to gather information before they make travel decisions.

Some studies have reviewed existing research on social media, however they noted that the role of social media in evaluating alternatives or influencing purchases is rarely studied, especially UGC [2], [3]. Therefore, this study has been conducted to fill the gap in the literature and location of study, Indonesia. Indonesia, becoming one of many countries that growing exponentially based on people utilizing the internet, especially social media. The study objective will be identifying and analyzing the UGC in Instagram, especially in tourism industries.

\section{LITERATURE REVIEW}

Prior to the presence of Internet, consumers have limited access in terms of decision making. Some relied on word-of-mouth, while others solely trust information came from the producers or as we know as advertising [4], [5]. The advent of social media to the Internet, has transformed marketing media from a business-to-consumer marketing to peer-to-peer generation and sharing of data. Crafting a marketing message and position it in front of the consumer has become difficult. Nowadays, consumers can access vast pool of data in the Internet to evaluate alternatives that affects their decision-making process [6]-[8]. One of the most popular social media content that related to peer-to-peer generation and sharing of data is User-generated-content (UGC). UGC is a new form of word-of-mouth boosted by the internet into a mass communications media with audiences from group of friends or thousands of online-but-connected strangers in social media [3], [9]. User-generated content (UGC) is a new type of word-of-mouth that rose up after the invention of the world wide web, which give ability to Internet users to share their reviews with millions of other people. In its simplest form, UGC is a media that has been created and/or shared online by a person. The types of media under the umbrella of UGC vary, with microformats moving into the mainstream due to the rise of mobile social media channels such as Facebook, Twitter, Snap Chat, and Instagram. Standard forms of UGC include simple text posts (e.g. status updates or Tweets), comments, photos, videos, and online ratings and reviews [3], [10], [11].

UGC has unrecognizably become a new marketing trend in Indonesia. Consumers' interests in UGC are based on what its offers; originality and fact based information. As brand-related UGC powered up on social media, today's marketers start to incorporate UGC as their word-of-mouth marketing. Word-of-mouth dispersion on the Internet has proven to be one of the most effective ways to share information about a product [12], [13]. The usage of UGC as marketing tool has raised the monetization of UGC. But, beyond the confines of the economic approach, the social intelligibility of affect has become one of the key issues in contemporary societies [14]. The development of the service sector in postindustrial economy, most are multiplication of jobs that demand the commercial use of feeling. Many of these services are now moving to the digital environment. Based on these perspectives, nowadays, many living persons, the prosumers of social media, create UGC willingly and on a daily basis [14]. 
Start from these persons willingness on creating UGC voluntarily, rose up new professions related to the creation of UGC. The formerly unpaid influencers in Instagram are now harvesting cash out of UGCs they created. These so called 'new professions' are divided into two large categories which are fashion/beauty and lifestyle/leisure travel. Henceforth, currently the incumbent of these professions is highly famous and have promising income.

In the millennials era, where browsing through social media has become part of daily routine, UGC has become highly trustworthy and trusted $40 \%$ more than information from traditional media sources (TV, print \& radio), including newspapers and magazines. Given their advertising savvy and skepticism around media, it is important for millennials to accept message through trusted sources. Direct conversations through friends and family are the most trusted UGC format. Though so, today's digital landscape, peer-created content or consumer to consumer marketing is the one that drives trust the most.

Realty Mogul has recently done an online survey among over 2,000 U.S. adults to understand the reason why nowadays people tend to choose to rent over buying a house. The result stated that millennials have strong feelings about renting to enable their lifestyle preferences. $49 \%$ of millennials (18-34) would rather spend the money on travelling than put it to buy a house. While the other $47 \%$ millennials $(18-34)$ would prefer to rent to be able to afford small luxuries (e.g. eating out, fancy coffee, avocado toast) daily. These newly shifted priorities happened not only in the U.S. but also in Indonesia. Nowadays recreation or another lifestyle activities are more important than freshly bought shirt.

As lifestyle and travelling rose up to become priorities for millennials generation, travelling UGC becomes very popular on Instagram. Most of the millennials are actively uploaded their content only during travelling holiday. This behavior is strongly correlated with millennials daily social media consumption and the basic need of travelling where photographs are a physical representation of reflecting the dimensions and touristic characteristics of individual experiences when travelling. Photographs are regarded as reflection of expectations, personality and values in describing tourists' experiences [12], [14]. Henceforth, travelling UGC is important for the millennials generation, so this study is made to validate the effectiveness of travelling UGC in Instagram as new marketing tool in the millennials era.

\section{METHOD}

This research is using mixed qualitative and quantitative method resulting in exploratory sequential design. Sequential form of research means that one type of data provides a basis for collection of another type of data [15]. Exploratory sequential design starts from desk research for literature review and observation for business analysis that contains both qualitative and quantitative data. While the analysis is done through a PESTEL framework and sustainable business strategies that are provided in the following section. The political factor is concerned with government regulations and legal issues that organizations must adhere to. From the political perspective, organizations must consider laws and regulations for their own countries.

\section{RESULTS and DISCUSSIONS}

The first section of results and discussions will be performed within analysis throughout qualitative methods followed by the elaboration and discussion of questionnaire results in the second section 


\subsection{PESTEL Analysis}

PESTEL analysis is a framework that categorizes and analyzes an important set of external forces (political, economic, sociocultural, technological, ecological, and legal) that might impinge [16].

\subsubsection{Political Factor}

Recently there has been a religion sentimentality during the 2017 Election of Jakarta Governor that leads to politic polarization. This polarization has started from rivalry of two large parties during the 2014 President Election that evolving into a cold war between nationalist and Moslem throughout the Jakarta Election. It is hard to melt down the current political tension in short time, given that the Presidential election will happen soon in 2019 [17], [18].

\subsubsection{Economic Factor.}

Indonesian has 5.07 percent economic growth throughout 2017; this number is a little more stable than the previous year of 2016. Nevertheless, this growth is followed by the shift between domestic consumption (food and clothing) into leisure and lifestyle consumption [19]-[21].

\subsubsection{Sociocultural Factor}

Throughout the first five months of 2017, Indonesian tourism growth has become one of the best in the world and is located between 20 biggest in Asia with 20 percent growth rate [21], [22]. Same with what it is mentioned in the previous point, this fact has also been supported by the fact that there has been a shift of priorities from the consumption of real objects (clothing) into pleasure consumption of lifestyle and leisure activity.

\subsubsection{Technological Factor}

Nowadays, Indonesia has 130 million active social media users or around 49 percent of total Indonesian population of 265.4 people. 120 million active social media users are accessing it through smartphone [9]. This fact shows that social media technology has become a part of people's daily life that can have big impact to change their paradigm [20], [22], [23]. 


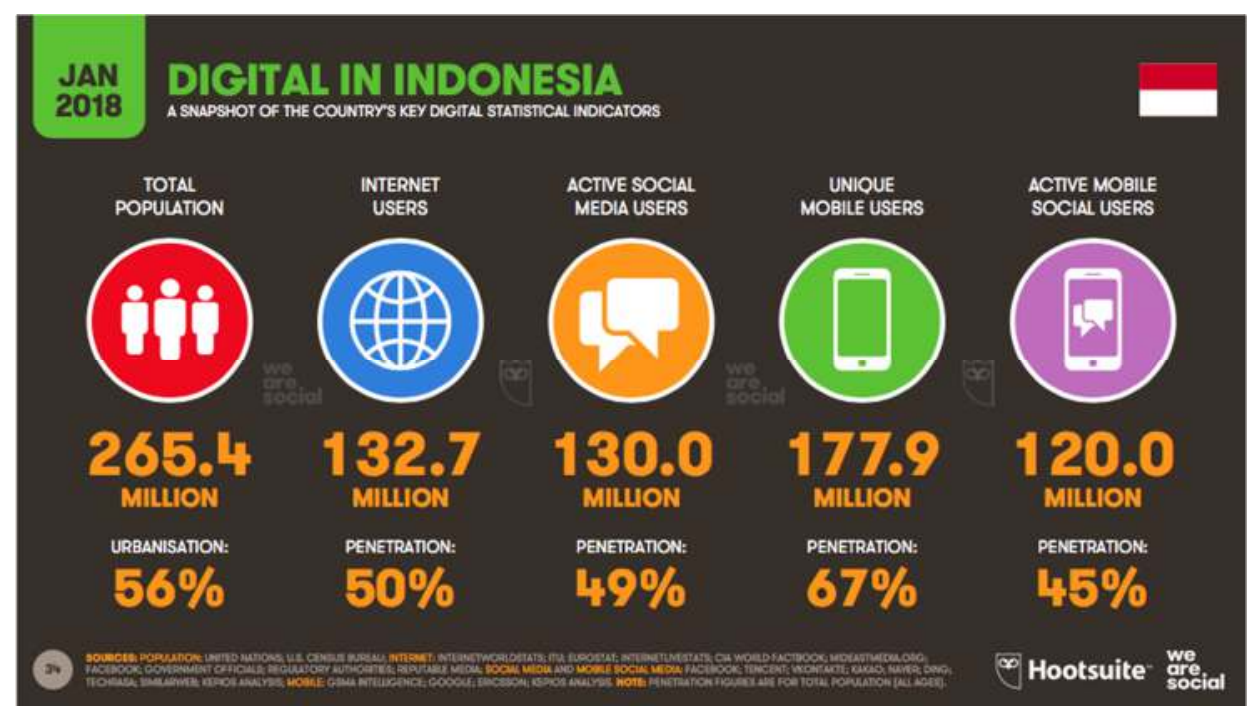

Figure 1. Digital Landscape in Indonesia.[9]

\subsubsection{Ecological Factor.}

50 percent of travel photography user service are millennials with ages between 25-34 years old (Frame A Trip, 2017). Moreover, as stated in the previous section, millennials tend to spend money to travel rather than to buy a house (Contiki, 2017). Furthermore, as millennials are closely related to social media, they would upload their travel pictures to social media and some of their picture would unrecognizably become UGC if they tagged places or services.

\subsubsection{Legal Factor}

User-Generated Content (UGC) usage in social media has been regulated in "The Notice of Minister of Communication and Informatics of The Indonesian Republic Number 5 Year 2016 About the Restrictions and Responsibility of Platform Providers and Merchant of Electronic Commerce that formed as User-Generated Content'[24]. This regulation is intended to protect the social media platform provider and merchant or entrepreneur out of misapplications of User-Generated Content from an irresponsible user. Moreover, this regulation would also clarify the restrictions and responsibility of the platform provider and merchant.

\subsection{Indonesian Consumer Characteristics}

UGC is a critical element for Indonesian digital marketer. Indonesians love to socialize and fancy social media. Mark plus Insight Youth Women Monitoring Study 2014 shows that the most active user of Internet is using it for more than 3 hours per day. As much as 84.5 percent Internet users are accessing it through social media. The following graphs shows netizen's most favorite activities on social media [25]. 


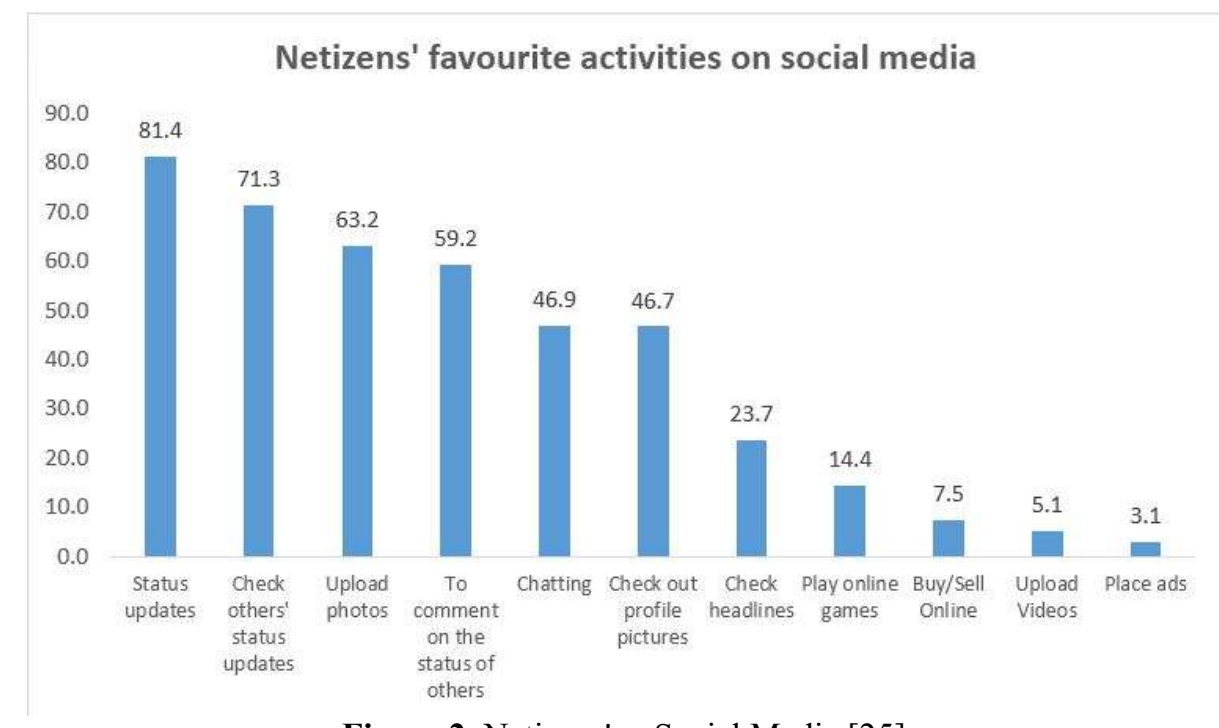

Figure 2. Netizens'on Social Media.[25]

We can exclude from the graphs that Internet users love to share their experiences. This habit would cause UGC to become the most successful online ad campaigns. As nowadays, Indonesian consumers are smarter and are not easily trust commercials that came from the producer itself. Observation shows that UGC has become daily consumption of social media users. UGC contents are varied and can be seen throughout different account owners. Influencers or top paid celebrities are paid by service/product providers to create UGC. Though so, most of social media users would still share voluntary real UGC in their private account. Generally, the difference between paid UGC and so-called 'real' UGC can be seen from the account owner's number of followers.

\subsection{Examples of User-Generated-Content in Indonesia}

AndienAisyah is one of the top paid singers that has over 1,4 million followers. The featured content is a sample of her Instagram post that contains paid UGC. She stated the Resort 'KamandaluUbud' where she has stayed during a holiday on the location column below her account name. To reaffirm, she also put the hashtag of \#Kamandalu on the end of her caption sentence. Furthermore, the picture on her UGC looked very aesthetic and was taken by a professional photographer. 


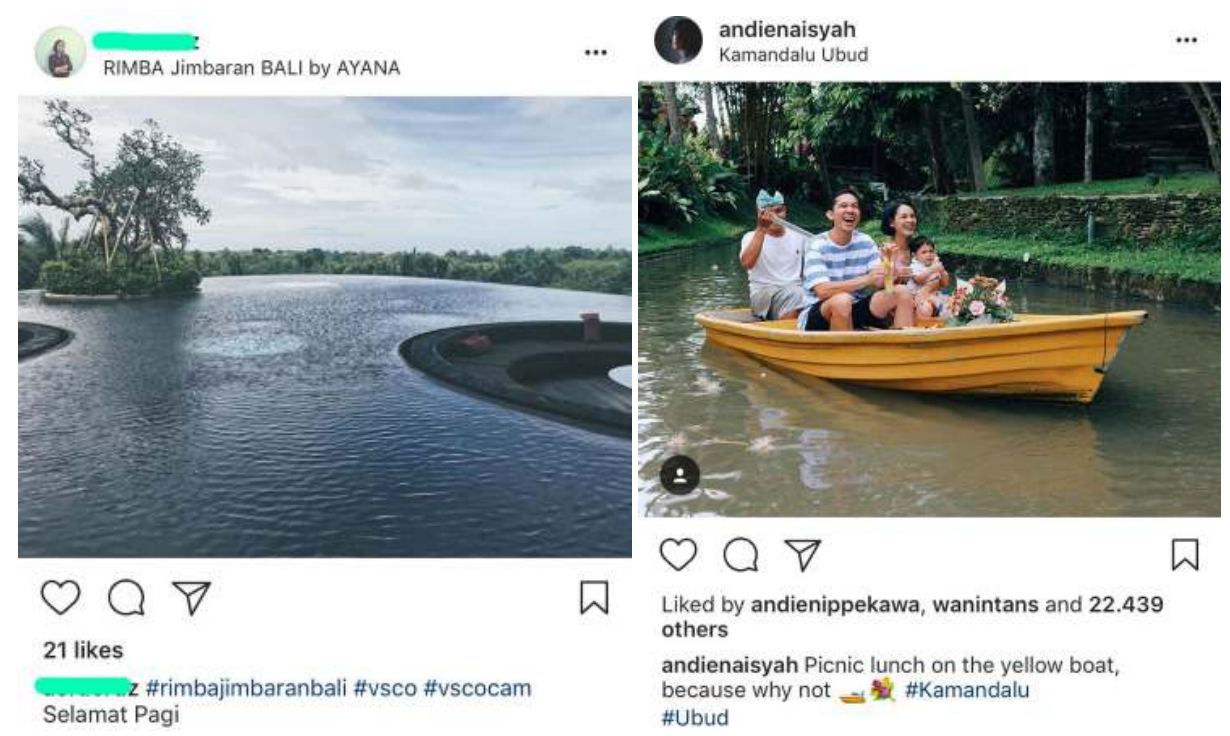

Figure 3. Examples of User-Generated-Content in Indonesia. (Source: Instagram)

While paid UGCs mostly seen on influencers account, real UGC mostly came from ordinary users' account of Instagram. As we can see in the second previous picture, the account owner only has 432 followers. She shares her experience when staying at the RIMBA Jimbaran BALI by AYANA Hotel. She took the picture with smartphone camera, not using professional camera as Andien did. She tagged the location 'RIMBA Jimbaran BALI by AYANA' on the location column below her account name, and put the hashtag \#rimbajimbaranbali as her caption. Unrecognizedably, she has voluntarily give free advertisement to RIMBA Jimbaran Bali by AYANA Hotel by uploading the picture as unpaid UGC.

\subsection{Consumer Relationship Psychological Factor}

Even though, marketing tactic such as Search Engine Optimization (SEO) can increase a website's traffic and content marketing could create consumer's interest, but UGC is the one that has main comparison in what do consumer think about a brand. UGC can provoke opinion and conversation between consumer in social media about brand or product. Thereby, with UGC, consumer can get complete fact and story about a product or a brand [25].

\subsection{Questionnaire Result Elaboration}

To validate above data acquired from qualitative study, quantitative study was implemented with the questionnaire deployment. The questionnaire consist of 27 questions and deployed to a total of 245 social media users varied within age range of 16 to 46 years old. 68.2 percent of respondents are students and 60.4 percent of respondents admit that they are accessing social media for more than three hours a day.

Types of social media accounts that these respondents have are Linkedin, Facebook, Instagram, Path, Twitter, Ask.fm, YouTube, Google+, Line, and Pinterest. But about 91.5 percent of respondents agree that Instagram is the most frequently open with longest 
attachment for more than 15 minutes a day. This fact shows that most respondents have stronger connection with their Instagram account rather than their other social media accounts.

This Instagram phenomenon creates a domino effect to other internet activities. When netizens are looking for new clothes, a new pair of shoes, hot gossip, beautiful villas to stay during the holiday, before or after they googled it, they searched it too in Instagram. So Instagram's role as social media where people share their daily activities or aesthetic photos tend to shift to become a one stop service to socialize, find travel information and shopping. As we can see now, UGC has been commonly used in Instagram as one of the manifestations of those mentioned new Instagram services.

Five communications and advertisement medias are mentioned in the questionnaire to get clearer view of which media has the largest impact to respondents' buying decisions. The medias are Radio, TV, Online advertisement, Social Media, Printed Media, and Words of mouth. Social media $(67.8 \%)$ and words-of-mouth $(80 \%)$ arise to be the most trusted advertisement medias that impacting respondents' buying decision. This results look connected to the statement that UGC is the new form of words-of-mouth. Henceforth, we can conclude that UGC in social media can be very effective in affecting consumers' buying decision.

Furthermore, in browsing activity, respondents agreed that browsing latest news (68.9 percent) is the most important activity while attached to Instagram. Second most important is to browse their homepage (58.4 percent) and Online store account page (43.3 percent). Surprisingly, according to the questionnaire result, browsing friends' and influencers' account page is considered not important enough with less than 40 percent vote. Meanwhile, respondents agreed that the posts that they saw from their friends' and influencers' account pages are the ones that most likely affect their buying decisions.

Last, respondents more likely to upload their travel activities (49.8 percent) more than their daily activities (19.2 percent). Product reviews are considered quite important with 40.9 percent vote. This sums up the conclusion of today's millennials generations interest in travelling.

\section{CONCLUSIONS}

User-generated content is a social phenomenon that arises due to the presence of the Internet and social media. The rapid growth of smartphone usage in Indonesia has also contributed to the deployment of UGC in Indonesia. Nowadays, UGC is one of the most effective marketing media of any marketing media. Why? The reason is because UGC offers factual informationthat creates deeper attachment to the product. When consumers feel attached to a product through UGC, then they would easily believe with the information conveyed so that marketing activities are done more effectively.

Millennials generation are very fond of travelling, according to the questionnaire result, uploading travelling activities to Instagram is a very important when it comes to online activity. Subsequently, based on the author's observation, most Instagram media users are more active in uploading their travelling activities to Instagram during and after travelling. The increasing number of social media users uploading photos of their travel activities will affects public interest to the world of tourism itself. The nature beauty, beautiful culture, historical monument, or amazing tourist attraction that the traveller's upload to Instagram will gain interest of the other Instagram users. As mentioned in previous section, in millenials era, on top of google, people tend to use Instagram to find informations. Therefore, the use of $\mathrm{UGC}$ in Instagram for the world of tourism and travelling is considered very effective to 
attract consumers let alone in Indonesia which has 265 million people with 16,056 Islands extending from Sabang to Merauke.

Although the development of UGC as a means of promotion is very effective to capture consumer interest, there is still considered a weakness in this means of promotion, namely the absence of patents for UGC makers. This absence made the UGC can be easily imitated or disseminated by irresponsible parties. Therefore, before creating a UGC, social media account users should know the consequences of his/her actions.

\section{REFERENCES}

[1] R. Williams, T. van der Wiele, J. van Iwaarden, and S. Eldridge, "The importance of user-generated content: the case of hotels," TQM J., vol. 22, no. 2, pp. 117-128, Mar. 2010.

[2] A. Barreda and A. Bilgihan, "An analysis of user-generated content for hotel experiences," J. Hosp. Tour. Technol., vol. 4, no. 3, pp. 263-280, Sep. 2013.

[3] D. C. Ukpabi and H. Karjaluoto, "What drives travelers' adoption of user-generated content? A literature review," Tour. Manag. Perspect., vol. 28, no. September 2017, pp. 251-273, Oct. 2018.

[4] T. (Jennifer) Ma and D. Atkin, "User generated content and credibility evaluation of online health information: A meta analytic study," Telemat. Informatics, vol. 34, no. 5, pp. 472-486, Aug. 2017.

[5] A. Geissinger and C. Laurell, "User engagement in social media - an explorative study of Swedish fashion brands," J. Fash. Mark. Manag. An Int. J., vol. 20, no. 2, pp. 177-190, May 2016.

[6] A. M. Sundjaja, F. L. Gaol, S. B. Abdinagoro, and B. S. Abbas, "The Behavior of Online Museum Visitors on Facebook Fan Page of the Museum in Indonesia," Binus Bus. Rev., vol. 8, no. 3, p. 237, Nov. 2017.

[7] S. Candra, "The use of IPA in bricks and clicks service quality (lesson learned from ICT shop," Far East J. Electron. Commun., vol. 15, no. 1, 2015.

[8] S. Candra, "The Evaluation of E-Passport Quality Using E-Government Quality Measurement (Case Study of E-Passport in \{DKI\} Jakarta)," Adv. Sci. Lett., vol. 22, no. 5, pp. 1360-1362, 2016.

[9] Simon Kemp, "Digital in 2018: World's internet users pass the 4 billion mark," We Are Social, 2018. [Online]. Available: https://wearesocial.com/blog/2018/01/globaldigital-report-2018.

[10] K. Crowston and I. Fagnot, "Stages of motivation for contributing user-generated content: A theory and empirical test," Int. J. Hum. Comput. Stud., vol. 109, pp. 89-101, Jan. 2018.

[11] M. Luca, "User-Generated Content and Social Media," in Handbook of Media Economics, Elsevier, 2015, pp. 563-592.

[12] A. N. Smith, E. Fischer, and C. Yongjian, "How Does Brand-related User-generated Content Differ across YouTube, Facebook, and Twitter?," J. Interact. Mark., vol. 26, no. 2, pp. 102-113, May 2012.

[13] L. Silva and H. Panahi, "Catch me if you can: Online protests on sites powered by user-generated content," Inf. \{\&\} Manag., vol. 54, no. 1, pp. 103-114, Jan. 2017.

[14] M. Zajc, "The Social Media Dispositive and Monetization of User-Generated Content," Inf. Soc., vol. 31, no. 1, pp. 61-67, Jan. 2015.

[15] J. W. Creswell, "Steps in Conducting a Scholarly Mixed Methods Study," DBER 
Speak. Ser., no. 48, p. 54, 2013.

[16] A. A. Thompson, M. A. Peteraf, J. Gamble, and A. J. Strickland III, Crafting and executing strategy: the quest for competitive advantage : concepts and cases, $21 \mathrm{st}$ ed. New York: McGraw-Hill Education, 2018.

[17] H. Affan, "Seperti apa wajah politik Indonesia setelah Pilkada Jakarta berakhir?," $B B C$ News Indonesia, 2017. [Online]. Available: https://www.bbc.com/indonesia/indonesia-39626091.

[18] J. A. Juneli, "Bagaimana Kondisi Sosial Politik di Indonesia?," Sosial Politik Universitas Gadjah Mada, 2017. [Online]. Available: https://sosialpolitik.filsafat.ugm.ac.id/2017/08/21/bagaimana-kondisi-sosial-politik-diindonesia/.

[19] S. R. D. Setiawan, "Ekonomi Indonesia 2017 Tumbuh 5,07 Persen, Tertinggi Sejak Tahun 2014," Kompas, 2018.

[20] D. Lestari and B. Aria, "Generasi Milenial Lebih Pilih Traveling Ketimbang Beli Rumah,” VIVA, 2017. [Online]. Available: https://www.viva.co.id/gayahidup/travel/984450-generasi-milenial-lebih-pilih-traveling-ketimbang-beli-rumah.

[21] S. T. Sulistiyono, "Masyarakat Sekarang Lebih Suka Rekreasi Dibanding Beli Baju Baru," Tribun News, 2017. [Online]. Available: http://www.tribunnews.com/bisnis/2017/08/15/masyarakat-sekarang-lebih-sukarekreasi-dibanding-beli-baju-baru.

[22] The Business Year, "Arief Yahya: Indonesia among the top 20 fastest growing Asian tourist destinations," The Business Year, 2018. [Online]. Available: https://www.thebusinessyear.com/indonesia-2018/arief-yahya-minister-of-tourism-ofindonesia/vip-interview.

[23] S. Agmasari, "Seperti Apa Tren Foto Liburan Anak Zaman Now?," Kompas, 2018. [Online]. Available: https://travel.kompas.com/read/2018/01/04/084700427/sepertiapa-tren-foto-liburan-anak-zaman-now-.

[24] K. Molina, "Indonesia Implements a Safe Harbor Policy for E-Commerce (Marketplace) Platforms," White and Case, 2017. [Online]. Available: https://www.whitecase.com/publications/alert/indonesia-implements-safe-harborpolicy-e-commerce-marketplace-platforms.

[25] Markplus Inc, "Why user generated content is ever more important for online marketers in Indonesia?," 2015. [Online]. Available: http://www.markplusinc.com/why-user-generated-content-is-ever-more-important-foronline-marketers-in-indonesia/. 